\title{
Boundary Layer Transition Experiments in Support of the Hypersonics Program
}

\author{
Scott A. Berry ${ }^{*}$ and Fang-Jenq Chen ${ }^{\dagger}$ \\ NASA Langley Research Center, Hampton VA, 23681 \\ Michael C. Wilder ${ }^{*}$ and Daniel C. Reda ${ }^{\S}$ \\ NASA Ames Research Center, Moffett Field CA, 94035
}

\begin{abstract}
Two experimental boundary layer transition studies in support of fundamental hypersonics research are reviewed. The two studies are the HyBoLT flight experiment and a new ballistic range effort. Details are provided of the objectives and approach associated with each experimental program. The establishment of experimental databases from ground and flight are to provide better understanding of high-speed flows and data to validate and guide the development of simulation tools.
\end{abstract}

\section{Nomenclature}

$X, Y, Z=$ Location on vehicle referenced from virtual origin

$\alpha=$ angle of attack (deg)

$\beta=$ angle of yaw (deg)

$k=$ protuberance height above the surface (in)

$\delta \quad=$ boundary layer thickness (in)

$\operatorname{Re}_{\theta} \quad=$ momentum thickness Reynolds number

$M_{e} \quad=$ Mach number at the boundary layer edge

$\delta^{*} \quad=$ displacement thickness

$\theta \quad=$ momentum thickness

$T_{e} \quad=$ temperature at the boundary layer edge

$T_{w} \quad=$ temperature at the wall

$V_{\text {cavity }}=$ cavity volume

$L, D, W=$ cavity length, depth, and width (in)

$R e_{k}=$ Reynolds number based on properties at trip height

\section{Introduction}

WASA's recent restructuring of its aeronautics programs was conducted in order to prioritize and pursue long1 term, cutting edge fundamental research in support of the broad aeronautics community. As recently presented at the $45^{\text {th }}$ Annual AIAA Aerospace Sciences Meeting, aeronautics research has been organized into four specific programs: Fundamental Aeronautics, Aviation Safety, Airspace Systems, and Aeronautics Testing. ${ }^{1}$ These four programs represent the core aeronautics competencies that are deemed appropriate to NASA's unique capabilities. Within the Fundamental Aeronautics Program, the research is grouped into four projects: hypersonics, supersonics, subsonic fixed wings, and subsonic rotary wings. The new emphasis for the fundamental aeronautics program is development of multidisciplinary capability critical to sustaining further aeronautics advancements. For the hypersonics project, ${ }^{2}$ fundamental research is planned for all disciplines that enable very high-speed flight (for instance for launch vehicles) and planetary entry systems. Experimental activities have been recently initiated in support of fundamental hypersonics research ${ }^{3}$ within the discipline of boundary layer transition. The present paper

\footnotetext{
*Aerospace Engineer, Aerothermodynamics Branch, M/S 408A, Senior Member AIAA.

$\dagger$ Aerospace Engineer, Flow Physics and Control Branch, M/S 170, Senior Member AIAA.

*Aerospace Engineer, Reacting Flow Environments Branch, MS 230-2, Senior Member AIAA.

${ }^{\S}$ Senior Staff Scientist, Space Technology Division, MS 229-3, Fellow AIAA.
} 
provides details of two experimental programs that will support the fundamental hypersonics effort: the HyBoLT (Hypersonic Boundary Layer Transition) flight experiment and new roughness-induced transition studies in the Ames ballistic range. These two efforts are intended to provide a better understanding of high-speed boundary layer transition and to provide data to validate and/or guide the development of engineering and/or simulation tools.

\section{Hypersonic Boundary Layer Transition}

Hypersonic boundary layer transition is a critically important discipline with potential impact on all future designs for high-speed applications. For instance, a spacecraft entering Earth's atmosphere initially experiences a heating environment associated with a laminar boundary layer. Eventually, as the atmosphere becomes denser and/or the vehicle surface becomes rougher, the boundary layer becomes turbulent and the heating rate at the surface can increase by a factor four or more. Our ability to understand and predict when this transition to turbulence and higher heating will occur has design implications for the thermal protection system (TPS) needed to protect the vehicle and crew during entry. Typically TPS designers try to use a conservative approach such as using an allturbulent heating profile to select material and size thickness, as was adopted for some of the recent X-vehicle designs (for instance X-34 ${ }^{4}$ ) and more recently for the Crew Exploration Vehicle (CEV). One advantage of an allturbulent design approach is that it avoids the issues associated with having to define boundary layer transition criteria. For CEV the all-turbulent approach provides the means to assess initial TPS concepts. However, as vehicle designs mature, quantification of when (during flight) the boundary layer will transition to the higher heating rates will typically allow for reduced TPS weight and thus provide a direct impact to the final design.

For smooth bodies, the transition process can generally be computationally modeled for simple shapes thanks to progress made on understanding the physical instability mechanisms within laminar boundary layers. ${ }^{5}$ Boundary layer disturbances, either excited by the outside environment (receptivity of pressure, velocity, or temperature fluctuations) or the surface (roughness), can exponentially grow (as wave-like structures) causing the eventual breakdown to turbulence. Computational tools are now available ${ }^{6}$ to determine if and when these instability waves (primarily Tollmein-Schlichting, crossflow, or Goertler type disturbances) will breakdown to secondary and/or nonlinear instabilities and then turbulence. These computational tools simulate the physical processes within the laminar boundary layer, but still must be calibrated against actual data. In the absence of large boundary layer modifiers (extreme roughness or noise) that encourage bypass mechanisms, stability calculations have been shown (by comparison to both ground-based and flight data) to accurately predict transition onset. ${ }^{7}$ Furthermore, recent advances ${ }^{8}$ have tried to account for small (or subcritical) distributed roughness as inputs to the transition prediction model, although the transient growth theory has not yet had the opportunity to be compared against flight results.

Most flight programs account for the vehicle surface roughness, as dictated by the state of the TPS, in development and application of a boundary layer transition criteria. The TPS roughness plays an integral role in determining the probable transition onset time during reentry. Most spacecraft designed for reentry have some form of inherent surface roughness, whether in the form of misaligned TPS tiles on the Shuttle Orbiters or, in the case of TPS designed for planetary entry or lunar return, irregularities on the surface formed during entry by ablation and/or spallation due to extremely high surface temperatures. Traditional ceramic-based TPS tiles such as those used on the Orbiters are susceptible to inadvertent roughness such as damage from launch in the form of cavities and/or gap filler protrusions. The inherent roughness is usually of a distributed nature, characteristically small and abundant. The inadvertent roughness is usually of a discrete nature, typically much larger in scale than distributed and isolated (or infrequent). For the Space Shuttle Orbiters, the slight misalignments (steps and gaps) between windward acreage TPS tiles represent the background distributed-roughness that in the absence of any large discrete trips will induce boundary layer transition at a Mach number on the order of 8 . On two occasions (STS-28 and 73) the Orbiters have experienced early boundary layer transition at Mach numbers nearer to 18 as a result of large protruding gap fillers.

As a result of the Columbia accident investigation, a concerted effort was expended, in support of the Shuttle Orbiter Return-to-Flight (RTF) program, on a boundary layer transition (BLT) prediction tool ${ }^{9}$ that is now part of a suite of engineering tools for assessing damage to the TPS. The group of analytic tools was developed for real-time mission support in the event of observed TPS damage, in order to determine if the vehicle is safe to fly as is, or if repair is required. ${ }^{10}$ The BLT Tool calculates the expected time of boundary layer transition during entry based on observed damage and/or repair locations and geometries. The program includes a database of computed boundary layer parameters that cover a range of nominal trajectories for entry and utilizes an interpolation tool to extract specific local properties for determining the boundary layer state during the mission trajectory. ${ }^{11}$ The BLT Tool is provided as a first step with which to establish the proper heating environment to baseline for the Cavity and 
Protuberance Heating tools. Calibration of the BLT Tool has been carried out by comparison of predicted transition results to several of the historical high Mach number flight cases. $^{12}$

Prior to STS-114, the issue of protruding gap fillers (discrete roughness) was viewed within the Shuttle community to be mainly of engineering interest as opposed to a safety of flight issue. Two large protrusions were identified during the mission $^{13}$ that were significantly larger than those previously found on post-flight ground inspections. The resulting BLT Tool prediction times were thus much earlier than any historical precedent that represents the basis for the assessing the aeroheating environments for the flight. Recognizing that a large uncertainty was associated with

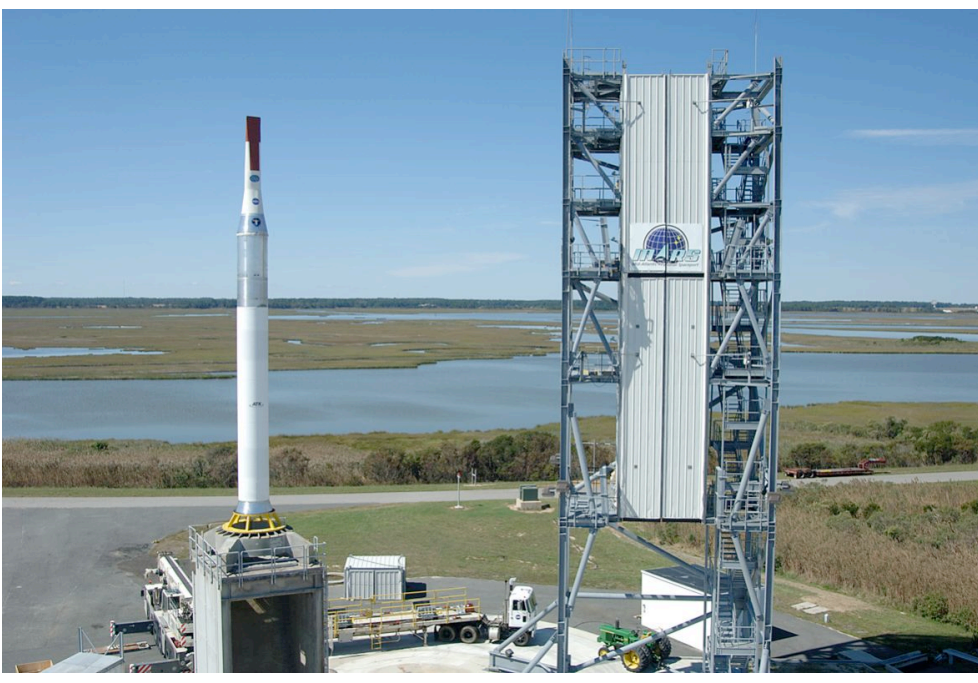

Figure 1. Mock-up of HyBoLT on the ALV X-1 pathfinder at Wallops Flight Facility

BLT predictions outside of prior experience, the Shuttle program decided it was safer to perform a risky in-space repair (to send an astronaut out to remove the gap fillers) instead of reentering with the gap fillers left in place. A post-flight close call investigation report, dated Nov. 28, 2005, states: "reducing BLT prediction uncertainty only marginally through targeted tests and/or analysis, if technically feasible and programmatically affordable (in both time and money), might provide the data necessary to allow an otherwise inconclusive assessment to be shown as acceptable for entry as-is. Such additional test and analyses seem prudent to provide helpful data in making a riskrisk trade when the choice is not as simple as that which was presented by the [protruding gap fillers] on STS-114." The present fundamental hypersonics experimental effort was established with this last statement in mind, with the hope of providing critical boundary layer transition data for validating and/or calibrating existing simulation and engineering tools.

\section{HyBoLT Flight Experiment}

\section{A. Introduction and Mission Objectives}

A flight of opportunity was provided through the termination of a scramjet-powered test vehicle that was to be the primary payload with the initial launch by ATK of a multi-stage rocket, the ALV X-1. The original offer was a ride of the Scramjet Flight Experiment (SFX) in exchange for NASA providing range support and launch-indemnification. NASA terminated the SFX program in March 2006 due to cost and schedule concerns, which left the ALV X-1 without a primary payload for the front of the rocket. The HyBoLT (Hypersonic Boundary Layer Transition) flight experiment developed as a replacement for SFX with the goal of having minimal impact to the ALV X-1 launch schedule. The ALV X-1 is currently scheduled to launch from NASA Wallops Flight Facility (WFF) on the northeastern shore of Virginia in the fall of 2007. Figure 1 shows a mock-up of HyBoLT on a near ready (pathfinder) version of ALV X-1 at the WFF launch facility. The HyBoLT

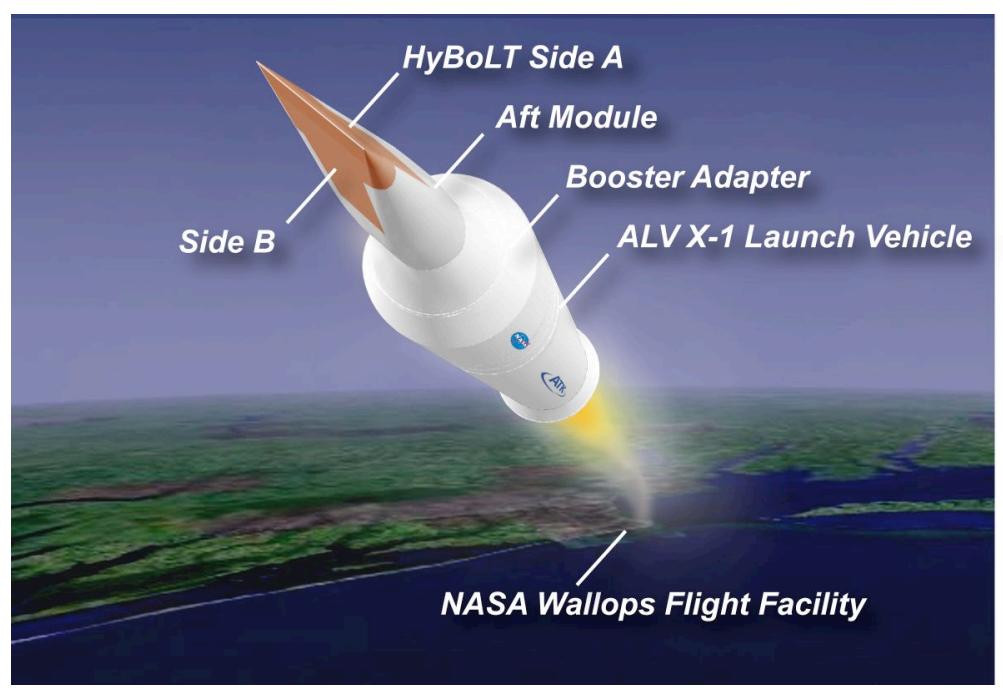

Figure 2. Artistic rendering of HyBoLT during launch from Wallops Flight Facility

American Institute of Aeronautics and Astronautics 
flight experiment was proposed to obtain (both engineering and simulation) code validation data for prediction of hypersonic boundary layer transition. The flight experiment actually has two separate sides with independent objectives, with one side being dedicated to investigating smooth wall transition (referred to as Side A) and the other discrete roughness transition (Side B).

\section{B. Vehicle Constraints and Geometry}

To minimize launch schedule impacts (and at the same time maximize the return on investment with the cancelled program), the decision was made to utilize the SFX nose cone design. This mature design had already gone through several detailed reviews. Any deviation from the

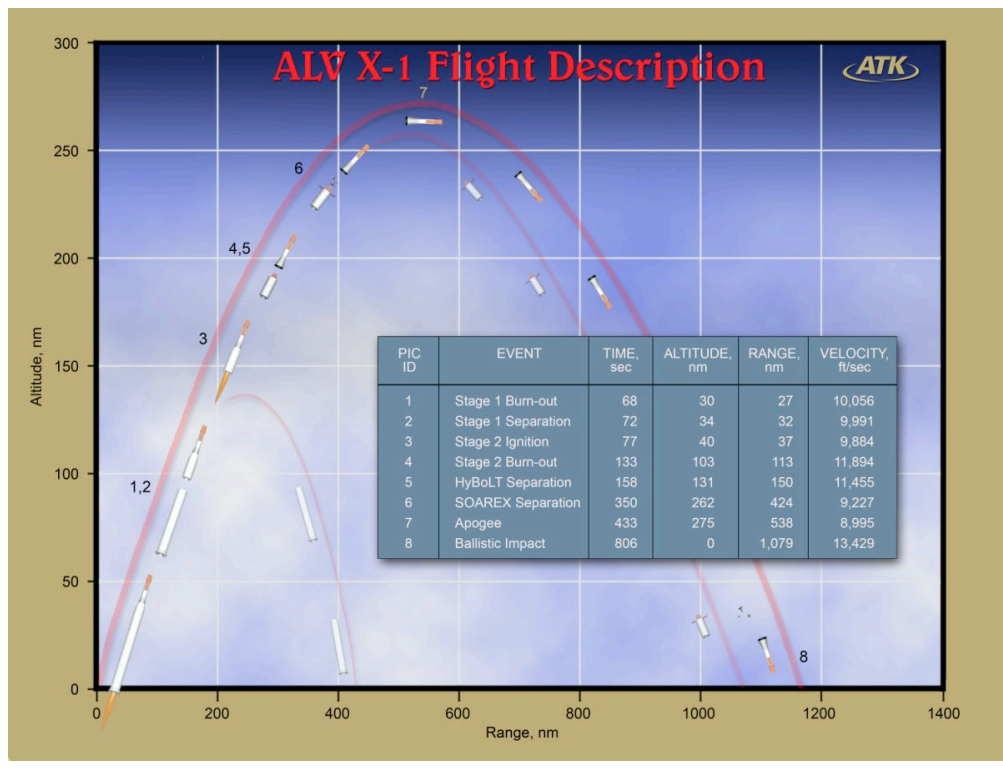

Figure 3. Preliminary ALV X-1 flight profile

SFX nose shape would have meant a new design and qualification effort and thus an immediate delay to the launch schedule. The nose geometry that was adopted by HyBoLT is shown in Figure 2, a conceptual image during launch. The forebody is a $6^{\circ}$ half-angle wedge shape with semi-conical contour on both shoulders. The leading edge has a radius of 0.15 inches. The experimental surfaces of interest, shown in copper color, are $1 / 2$-inch thick flat copper plates that extend downstream from the leading edge a total of 90 inches. The white color regions in the sketch are aluminum structure protected by cork ablative insulation. The two flat wedge surfaces, each bounded between the conical shoulders, provide the two independent sides that constitute the HyBoLT flight experiment. HyBoLT is attached to the ATK launch vehicle (ALV X-1) with an aft module and booster adapter.

The flight profile for the multi-stage ALV X-1 rocket is shown in Figure 3. This rocket is designed to have a gross weight of 43,000 lbs., a length of $54 \mathrm{ft}$., a diameter of $50 \mathrm{in}$., and is expected to achieve a maximum Mach number of 11.4 and altitude of 275 nautical miles. The HyBoLT nose cone stays attached to the ALV X-1 through second-stage burn out with separation at 158 seconds after lift-off. HyBoLT is not recoverable with splashdown in the Atlantic ocean occurring northeast of Antigua. The critical data collection window for HyBoLT is the first 65 seconds, as shown in Figure 4 along with key trajectory analysis points, which are also listed in Table 1. The nominal angle of attack is nearly zero throughout the flight profile and thus both sides should experience similar environments.

HyBoLT has a dedicated data acquisition and telemetry system that includes on-board processing to provide compression of high-frequency content to allow all data to fit within telemetry reception limits. Details of the instrumentation will be discussed in greater detail in the sections to follow. Additional important measurements for the flight (for instance, Mach number, Reynolds number, and angle of attack)

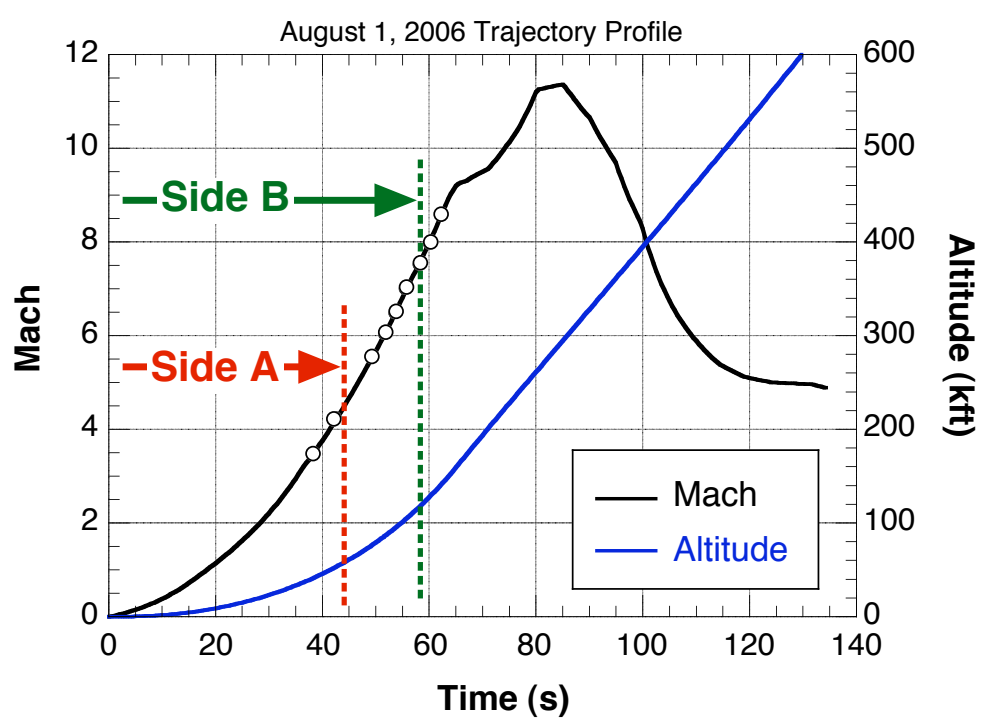

Figure 4. HyBoLT trajectory points and data criticality window 
Table 1. Key nominal trajectory points prior to Stage 1 burn-out

\begin{tabular}{||c|c|c|c|c|c|c||}
\hline $\begin{array}{c}\text { TIME } \\
(\mathrm{S})\end{array}$ & MACH & $\begin{array}{c}\text { ALTITUDE } \\
(\mathrm{FT})\end{array}$ & RANGE (NMI) & $\begin{array}{c}\text { VELOCITY } \\
(\mathrm{FT/SEC})\end{array}$ & $\begin{array}{c}\text { ANGLE OF } \\
\text { ATTACK (DEG) }\end{array}$ & $\begin{array}{c}\text { REYNOLDS } \\
\text { NUMBER }\end{array}$ \\
\hline 35.5 & 3.0 & 34468 & 3.7 & 2961.3 & 0.03 & $7.42 \mathrm{E}+06$ \\
\hline 42.5 & 4.2 & 52993 & 6.3 & 4063.6 & 0.03 & $4.32 \mathrm{E}+06$ \\
\hline 49.2 & 5.5 & 76025 & 9.8 & 5362.2 & 0.04 & $1.85 \mathrm{E}+06$ \\
\hline 51.5 & 6.0 & 85599 & 11.3 & 5888.1 & -0.13 & $1.27 \mathrm{E}+06$ \\
\hline 54.0 & 6.6 & 96438 & 13.1 & 6490.7 & -0.17 & $8.28 \mathrm{E}+05$ \\
\hline 56.0 & 7.1 & 106032 & 14.6 & 7029.6 & -0.20 & $5.66 \mathrm{E}+05$ \\
\hline 58.0 & 7.5 & 116359 & 16.3 & 7611.9 & -0.23 & $3.63 \mathrm{E}+05$ \\
\hline 60.0 & 8.0 & 127482 & 18.2 & 8252.2 & -0.27 & $2.29 \mathrm{E}+05$ \\
\hline 62.0 & 8.5 & 139489 & 20.2 & 8965.2 & -0.30 & $1.42 \mathrm{E}+05$ \\
\hline
\end{tabular}

will be obtained from post-flight "best-estimated trajectory" reconstruction of the entire integrated rocket data obtained from (1) the ALV-X1 telemetry which includes an inertial navigation system; and/or (2) ground-based radar tracking facilities.

\section{Science Objectives and Experimental Design \\ 1. Side A Natural}

The objective for Side A is to obtain hypersonic boundary layer transition data which is used to understand natural transition flow physics and for code validation. To support this activity, in-flight measurement of smooth wall transition characteristics (transition front movement, disturbance frequencies and movement, and boundary layer profiles) and freestream disturbance levels are planned. To insure that the measured transition onset results are in close agreement with the predictions based on stability theory ${ }^{7}$, strict smoothness requirements have been specified for Side A: surface finish of $16 \mu$-in RMS over the first 40-in and $32 \mu$-in RMS thereafter; no forward facing steps, only aft facing steps of 0.01-in or less; no gaps over the first 60 -in with the maximum allowable gap thereafter (to allow for thermal growth) is 0.10 -in; and for waviness, only 0.00025 -in over 0.5 -in for short waves and 0.005-in over 6-in for long waves are allowed.

\section{Transition Prediction}

Transition predictions based on boundary layer stability computations (unpublished work by Dr. Balakumar using the $\mathrm{e}^{\text {Malik3d }}$ code ${ }^{14}$ ) indicate that, due to pressure gradients produced by the leading edge corner and conical shoulder, transition on HyBoLT Side A will be dominated by crossflow instabilities occurring off-centerline in the Mach number range of 2.5 to 4.5 with the unit Reynolds number changing from $7.8 \times 10^{6} / \mathrm{ft}$ to $2.5 \times 10^{6} / \mathrm{ft}$. The transition stability analysis also indicates that, due to the combined effects of cold wall and leading edge bluntness, the growth of $1^{\text {st }}$ or $2^{\text {nd }}$ mode TollmienSchlichting waves are not expected to be significant enough to cause boundary layer transition anywhere on Side A up to Mach 8 during the flight. Therefore, the experimental plan for Side A is mainly concentrated to characterize crossflow instabilities.

Because of symmetry, transition prediction results are plotted on the upper half (positive Y) only in Figure 5, which shows the top view of Side A. Note that the coordinate is stretched in the Y-direction in this plot. The virtual leading edge (if sharp) is located at $\mathrm{X}=0$ inch while the actual blunt leading edge is at $\mathrm{X}=1.285$ inches. The trapezoidal region bounded between two inclined red lines from the leading edge to 90.0 inches is the flat plate portion of the

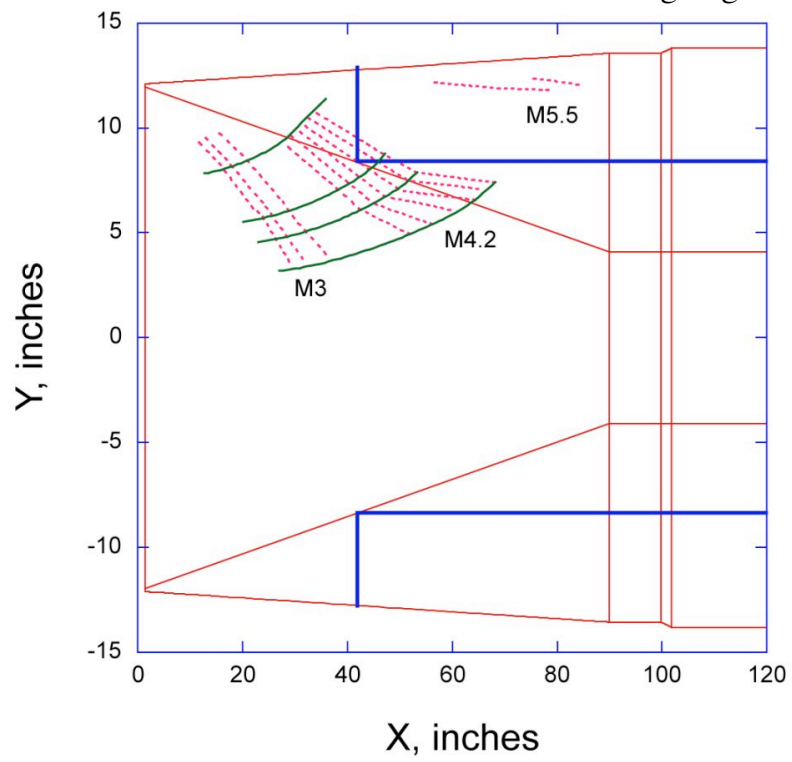

Figure 5. Side A transition prediction results 
copper experimental plate. This plot shows for Side A the predicted transition front movement as a function of Mach number. The solid green lines represent the local streamlines in this outboard region, while the dashed red lines represent constant values of disturbance growth (n-factors between 6 and 11). Since most of the predicted transition front locations for Mach 3.0 and 4.2 take place on the outboard portion of the flat section, the critical transition detection sensors are concentrated in this region for the Side A experiment. Note that for Mach 5.5, transition is predicted to occur on the conical shoulders, which is covered by surface thermal insulation (outboard of the blue lines in Figure 5), and thus is outside the region of interest for this experiment.

\section{Instrumentation}

The goals for the Side A experiment are to measure boundary layer transition location, fluctuation intensity, disturbance frequencies and propagation speed and direction, plus boundary conditions that consist of surface temperature distribution, surface pressure distribution, boundary layer profile, and flow direction. An array of surface flush mounted thermocouples will provide transition front movement results. Specially designed surface hot-film sensors are included to detect stationary and/or traveling waves. In addition, dynamic pressure sensor arrays will provide phase angle and phase velocity information of any traveling waves.

The instrumentation layout for HyBoLT Side A is shown in Figure 6. Side A instrumentation includes both low- and high-frequency sensors. The low-frequency sensors are sampled at 300 samples per second (sps) or less and provide time-averaged observations of transition location, surface pressure distribution, boundary layer profile, and flow direction. High-frequency sensors are sampled at either $20 \mathrm{kHz}$ or $100 \mathrm{kHz}$ and are used to identify frequencies, wave propagation speeds, direction and types of crossflow instabilities in order to determine the reasons for changes in the time-averaged observations.

\section{Low-frequency instrumentation}

Transition front mapping will be performed with an array of 77 thermocouples. All thermocouples are surface flush-mounted except one located just under the surface on the HyBoLT leading edge. A total of 22 surface static pressure ports are distributed on the shoulder sides and downstream of the sensor layout region to avoid any possibility of contamination of disturbances from these pressure ports. Two pairs of pressure ports along the centerline on Side A and Side B are used to collect differential pressure for independent verification of the ALV X-1 angle of attack, $\alpha$, during the flight test. Another two pairs of pressure ports on the opposite shoulder edges are used to measure the angle of yaw, $\beta$. A 'probeless' pressure rake, as shown in Figure

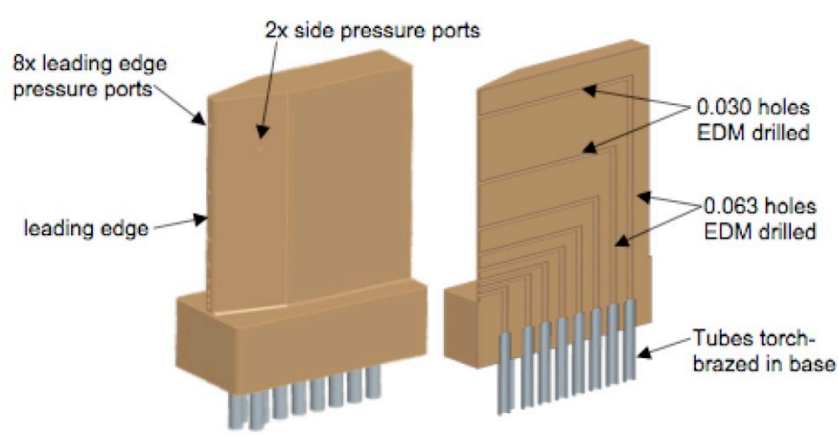

Figure 7. Side A boundary layer pressure rake 
7 , which is approximately 2 -in high by 0.5 -in wide by 2 -in long, is used to measure the boundary layer profile. A pair of pressure ports on the rake's opposite wedge side surfaces is used to determine the mean flow direction towards the top of the boundary layer. A second version of this boundary layer rake is located on centerline of Side B.

\section{High-frequency instrumentation}

A dynamic pressure probe stand equipped with a high frequency dynamic pressure transducer $(2.5$-in high by 0.75 -in wide by 1.625 -in long), as shown in Figure 8 , is used to monitor the freestream disturbance levels outside the boundary layer. The tip of the transducer is recessed 0.175 inches from the front surface and protected by a ceramic sleeve to alleviate heat load damage to the sensing element.

A row of six dynamic pressure transducers flush mounted on the port side (negative $\mathrm{Y}$ ) at $\mathrm{X} \approx 20$ inches, as shown in Figure 6, are used to monitor any possible disturbances coming from the leading edge corner. Another four dynamic pressure transducers are distributed near the edge of the experimental plate to monitor surface pressure fluctuations. Two threedynamic-pressure gages, that have three dynamic pressure transducers each in triangular formation at a spacing less than one wavelength of a crossflow vortex as shown in Figure 9, are located in the crossflow region. The top surface is flush mounted at locations

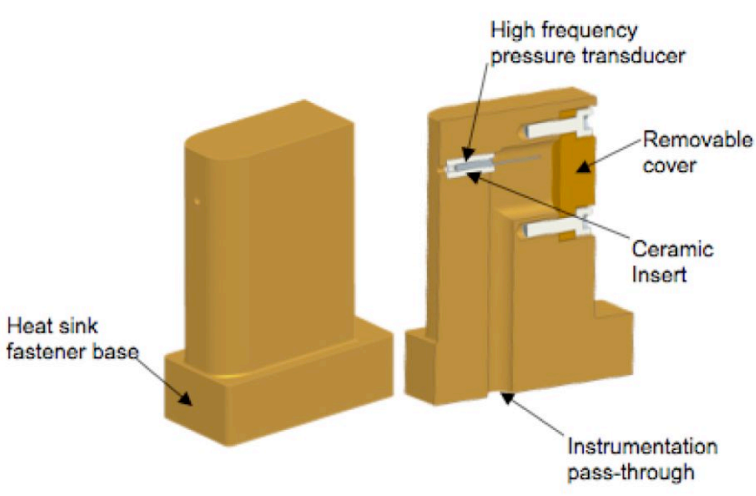

Figure 8. Side A freestream dynamic pressure probe on the starboard and port sides of the experimental plate and are used to measure the wave velocity and direction (phase velocity) of crossflow instabilities.

Surface hot-film gages that have three active filaments located inside one wavelength (predicted for crossflow disturbance) along the sensor centerline and three passive filaments distributed on the top surface of a quartz plug are shown in Figure 10. Two of these hot-film sensors are located in the crossflow region and designed to determine the crossflow instability (stationary or traveling) characteristics. The function of passive filaments is to measure local surface temperatures for adjustment of proper compensation of the active filaments. The hot-film gages are also used to detect the occurrence of boundary layer transition by the change of RMS levels of their AC output.

One final high frequency measurement is a one-axis vibrometer (Z-axis, $100 \mathrm{kHz}$ ) that is used to monitor the vibration of the experimental plate. All high-frequency content will be processed onboard to compress the data to the $5 \mathrm{Mbits} / \mathrm{sec}$ telemetry bandwidth limit. The processed data include spectral averaging of power spectral densities (PSD), correlations in space, and statistics, and will be used to document the physics of the transition process as completely as possible. Since the transition physics will change appreciably as the Mach number is

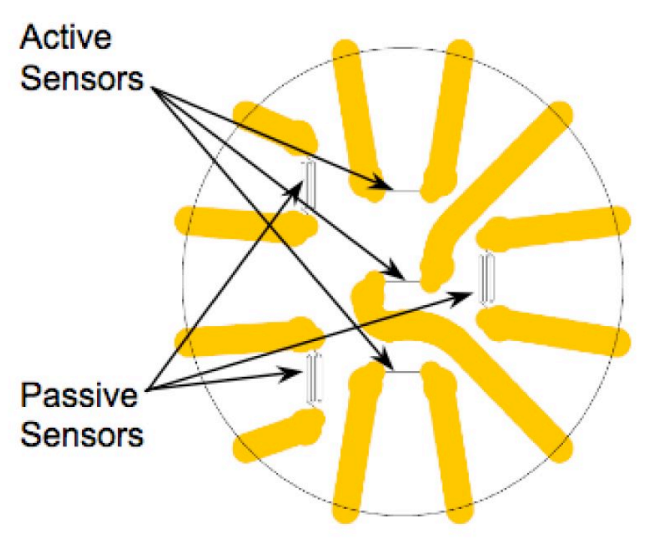

Figure 10. Side A surface hot-film plug 
increasing, any real-time analysis will be accomplished within the timestep equivalent of a change in Mach number of 0.02 ; that is, within 104 milliseconds (ms). One selected $5 \mathrm{kHz}$ channel will be downlinked in total to the ground station for post-flight post-processing to verify onboard data processing.

\section{Post-Flight Analysis}

As part of the post-flight data analysis for Side A, a wind tunnel experiment is planned for the LaRC Mach 3.5 Supersonic Low Disturbance Tunnel (SLDT) with possible companion efforts in other facilities. The goal of this post-flight effort is to complement the flight measurement results with data only obtainable under steady state, controlled conditions from ground-based facilities. A highly instrumented and cooled model will be designed based on results of wind tunnel blockage studies currently underway. Due to model size and quiet Reynolds number limits of the SLDT, direct comparisons of results at matching Reynolds numbers between flight and wind tunnel might be difficult. Therefore, whether the study should be carried out on a geometrically scaled HyBoLT model or on an appropriate geometry designed to exercise particular physical flow mechanism(s) of interest (e.g., crossflow) is currently under consideration. In either case, measurements will include mean boundary layer profile data and, possibly, some low amplification dynamic fluctuation data (due to lower Reynolds number) all obtained with miniature pitot and calibrated hot wire probes. Optional provisions for various surface flow visualization and optical flow field measurement methods are also under consideration. Information that can reasonably be expected to be obtainable pending the finalization of model design implementation details include the effects of: surface temperature, model pitch and yaw, leading edge and corner sphere radii, surface non-uniformities (roughness, waviness, gage installation roughness, etc), and measurement of the response characteristics for flight-similar hot film and temperature sensors.

\section{Side B Rough}

HyBoLT Side B was proposed to provide flight data comparing the relative effectiveness of various boundary layer (BL) trips relevant to the Shuttle Return to Flight (RTF) program. The Side B science objective is to obtain hypersonic boundary layer data from a known fixed transition position using boundary layer trips representative of damage (protrusions or cavities) to Shuttle Thermal Protection System (TPS). This data will support engineering code validation for the RTF BLT tool. ${ }^{9}$

The Side B roughness experiment has three separate discrete BL trips selected for side-by-side comparison. Two trips are used to compare protuberances of the same height (a gap filler type representing flight versus a ground-based "pizza box") and the third trip is a cavity designed (based on ground data) to trip at nearly the same point in the trajectory as the protuberances. The gap filler and cavity represent realistic damage scenarios for the Shuttle program and the new in-flight assessment capability developed as a result of the Columbia accident investigation. The cavity is located on centerline, while the protuberances are placed 5-in on either side of centerline, all at the trip station 20 inches back from the leading edge, as shown in Figure 11. These three BL trips

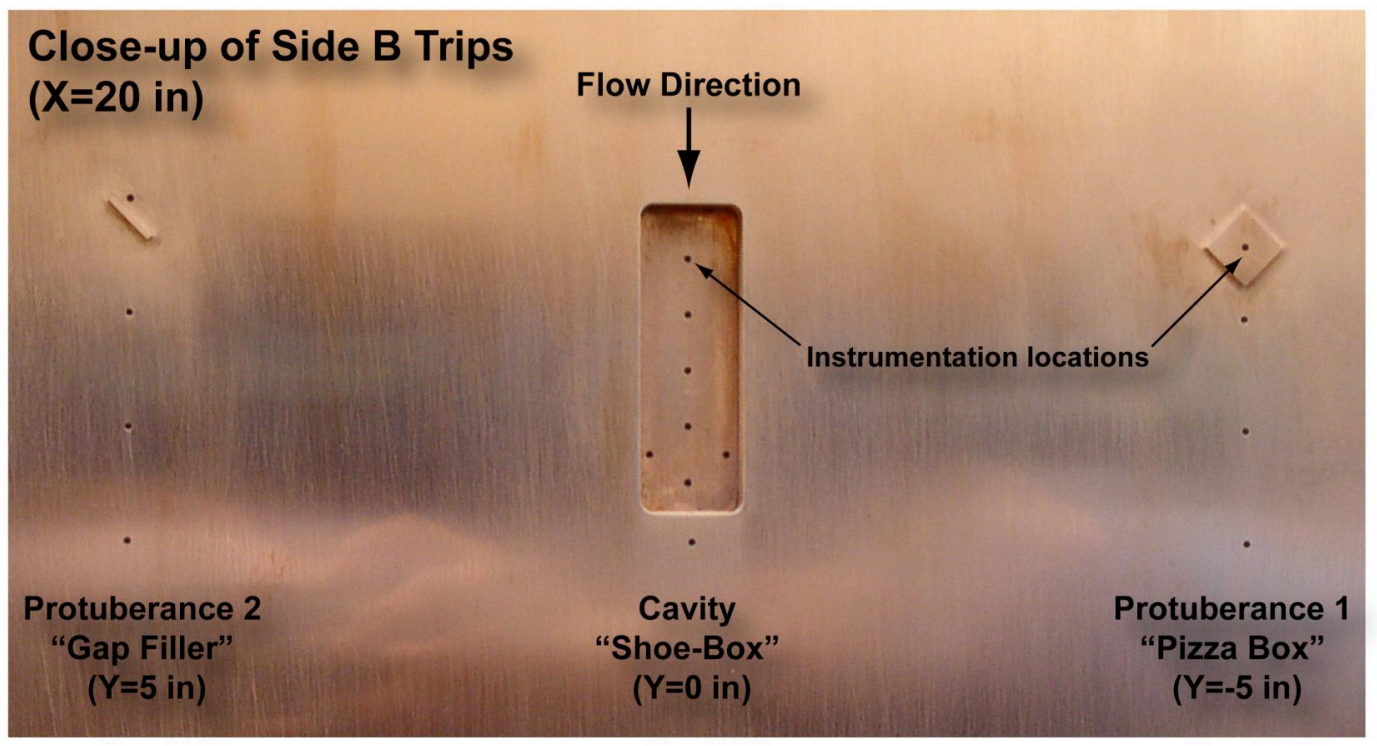

Figure 11. Side B roughness elements 
were all designed and machined as an integral part of the flat copper plate used for the Side B assembly.

\section{Trip Sizing}

The trips used for HyBoLT Side B have been sized based on the approach and methodology of the RTF BLT Tool Version 1. ${ }^{9}$ For protuberances, the trip height $(\mathrm{k})$ is predicted, based on a twosigma confidence level, to initiate the onset of transition based on 27 times the boundary layer thickness $(\delta)$ divided by the momentum thickness Reynolds number over the edge Mach number $\left(\mathrm{Re}_{\theta} / \mathrm{M}_{\mathrm{e}}\right)$. A similar correlation for cavities has been generated from the ground-based data ${ }^{15}$ as part of a planned update to Version 2 the BLT Tool (currently unpublished) using the cavity volume (V). The local parameters used to generate the RTF BLT correlations were based on the engineering code, LATCH, while the present HyBoLT parameters used to size the trips are based on viscous CFD solutions. The inconsistency between correlation development and application is initially acceptable due to the relative nature of the resulting data. Based on the groundbased data and correlations, the transition front movement behind all three trips should begin at about the same time during flight and the absolute time in comparison to expectations is less important. The impact of using viscous CFD solutions for extracting the local properties will be further investigated as the RTF BLT Tool is upgraded to Version 2, which is based solely on a CFD database.

Tables 2 and 3 provide the local boundary layer edge properties extracted from the CFD solutions for the nominal trajectory at the trip locations. The relevant parametric space for the Orbiter is values of $\mathrm{Re}_{\theta} / \mathrm{M}_{\mathrm{e}}$ between 50 and 200 (with $\mathrm{M}_{\mathrm{e}}$ on the order of 2.8) and values of $\mathrm{k} / \delta$ between 0.2 and 1.2. A quick scan of the trajectory points shown in Tables 2 and 3 reveal that Shuttle-like edge Mach numbers (roughly $\mathrm{M}_{\mathrm{e}}=2.8$ ) are obtained at the trip locations between Mach 6.5 and
Table 2. Local edge properties at key trajectory points for outboard trip station $(X=20 \quad Y= \pm 5)$

\begin{tabular}{||c|c|c|c|c|c|c||}
\hline \hline Mach & $\delta$ (in) & $\delta^{*}$ (in) & $\theta$ (in) & $\mathrm{Re}_{\theta} / \mathrm{M}_{\mathrm{e}}$ & $\mathrm{M}_{\mathrm{e}}$ & $\mathrm{T}_{\mathrm{e}} / \mathrm{T}_{\mathrm{w}}$ \\
\hline 3.0 & 0.0338 & 0.0124 & 0.0039 & 678.31 & 1.996 & 1.017 \\
\hline 4.2 & 0.0591 & 0.0190 & 0.0072 & 394.63 & 2.300 & 1.401 \\
\hline 5.5 & 0.1216 & 0.0323 & 0.0146 & 208.73 & 2.560 & 1.972 \\
\hline 6.0 & 0.1508 & 0.0424 & 0.0195 & 161.33 & 2.632 & 2.247 \\
\hline 6.5 & 0.1973 & 0.0542 & 0.0253 & 125.84 & 2.733 & 2.512 \\
\hline 7.0 & 0.2508 & 0.0699 & 0.0326 & 99.13 & 2.837 & 2.775 \\
\hline 7.5 & 0.3559 & 0.1029 & 0.0438 & 77.65 & 3.036 & 3.013 \\
\hline 8.0 & 0.4680 & 0.1495 & 0.0565 & 60.80 & 3.275 & 3.200 \\
\hline 8.5 & 0.5767 & 0.2046 & 0.0697 & 47.32 & 3.535 & 3.350 \\
\hline \hline
\end{tabular}

Table 3. Local edge properties at key trajectory points for centerline trip station $(\mathrm{X}=20 \mathrm{Y}=\mathbf{0})$

\begin{tabular}{||c|c|c|c|c|c|c||}
\hline \hline Mach & $\delta$ (in) & $\delta^{*}$ (in) & $\theta$ (in) & $\mathrm{Re}_{\theta} / \mathrm{M}_{e}$ & $\mathrm{M}_{e}$ & $\mathrm{~T}_{e} / \mathrm{T}_{\mathrm{w}}$ \\
\hline 3.0 & 0.0358 & 0.0135 & 0.0043 & 779.89 & 1.947 & 1.039 \\
\hline 4.2 & 0.0631 & 0.0208 & 0.0077 & 436.77 & 2.282 & 1.413 \\
\hline 5.5 & 0.1249 & 0.0338 & 0.0153 & 220.66 & 2.548 & 1.982 \\
\hline 6.0 & 0.1542 & 0.0439 & 0.0202 & 169.50 & 2.618 & 2.260 \\
\hline 6.5 & 0.2019 & 0.0563 & 0.0263 & 132.30 & 2.718 & 2.526 \\
\hline 7.0 & 0.2721 & 0.0750 & 0.0341 & 105.99 & 2.849 & 2.765 \\
\hline 7.5 & 0.3475 & 0.1028 & 0.0450 & 80.16 & 2.996 & 3.059 \\
\hline 8.0 & 0.4680 & 0.1514 & 0.0581 & 63.12 & 3.246 & 3.238 \\
\hline 8.5 & 0.5847 & 0.2111 & 0.0714 & 49.52 & 3.526 & 3.362 \\
\hline \hline
\end{tabular}

Table 4. Local edge properties at key trajectory points for centerline trip station $(\mathrm{X}=\mathbf{2 0} \mathrm{Y}=\mathbf{0})$

\begin{tabular}{||c|c|c|c|c|c|c||}
\hline \hline Mach & $\mathrm{k}_{\text {inc }}$ (in) & $\mathrm{k}_{\text {inc }} / \delta$ & $\mathrm{V}_{\text {cavity }}$ & $\mathrm{L}$ (in) & $\mathrm{D}$ (in) & $\mathrm{W}$ (in) \\
\hline 3.0 & 0.0012 & 0.0346 & 0.0001 & 0.1094 & 0.0150 & 0.0365 \\
\hline 4.2 & 0.0039 & 0.0618 & 0.0011 & 0.2927 & 0.0401 & 0.0976 \\
\hline 5.5 & 0.0153 & 0.1224 & 0.0309 & 0.8784 & 0.1203 & 0.2928 \\
\hline 6.0 & 0.0246 & 0.1593 & 0.0872 & 1.2407 & 0.1700 & 0.4136 \\
\hline 6.5 & 0.0412 & 0.2041 & 0.2860 & 1.8434 & 0.2525 & 0.6145 \\
\hline 7.0 & 0.0693 & 0.2547 & 0.9485 & 2.7489 & 0.3766 & 0.9163 \\
\hline 7.5 & 0.1171 & 0.3368 & 2.9483 & 4.0118 & 0.5496 & 1.3373 \\
\hline 8.0 & 0.2002 & 0.4278 & 10.0396 & 6.0356 & 0.8268 & 2.0119 \\
\hline 8.5 & 0.3188 & 0.5452 & 30.4456 & 8.7362 & 1.1967 & 2.9121 \\
\hline
\end{tabular}

Table 5. Local edge properties at key trajectory points for outboard trip station $(X=20 \quad Y= \pm 5)$

\begin{tabular}{||c|c|c|c|c|c|c||}
\hline \hline Mach & $\mathrm{k}_{\text {inc }}$ (in) & $\mathrm{k}_{\text {inc }} / \delta$ & $\mathrm{V}_{\text {cavity }}$ & $\mathrm{L}$ (in) & $\mathrm{D}$ (in) & $\mathrm{W}$ (in) \\
\hline 3.0 & 0.0012 & 0.0346 & 0.0001 & 0.1094 & 0.0150 & 0.0365 \\
\hline 4.2 & 0.0039 & 0.0618 & 0.0011 & 0.2927 & 0.0401 & 0.0976 \\
\hline 5.5 & 0.0153 & 0.1224 & 0.0309 & 0.8784 & 0.1203 & 0.2928 \\
\hline 6.0 & 0.0246 & 0.1593 & 0.0872 & 1.2407 & 0.1700 & 0.4136 \\
\hline 6.5 & 0.0412 & 0.2041 & 0.2860 & 1.8434 & 0.2525 & 0.6145 \\
\hline 7.0 & 0.0693 & 0.2547 & 0.9485 & 2.7489 & 0.3766 & 0.9163 \\
\hline 7.5 & 0.1171 & 0.3368 & 2.9483 & 4.0118 & 0.5496 & 1.3373 \\
\hline 8.0 & 0.2002 & 0.4278 & 10.0396 & 6.0356 & 0.8268 & 2.0119 \\
\hline 8.5 & 0.3188 & 0.5452 & 30.4456 & 8.7362 & 1.1967 & 2.9121 \\
\hline
\end{tabular}




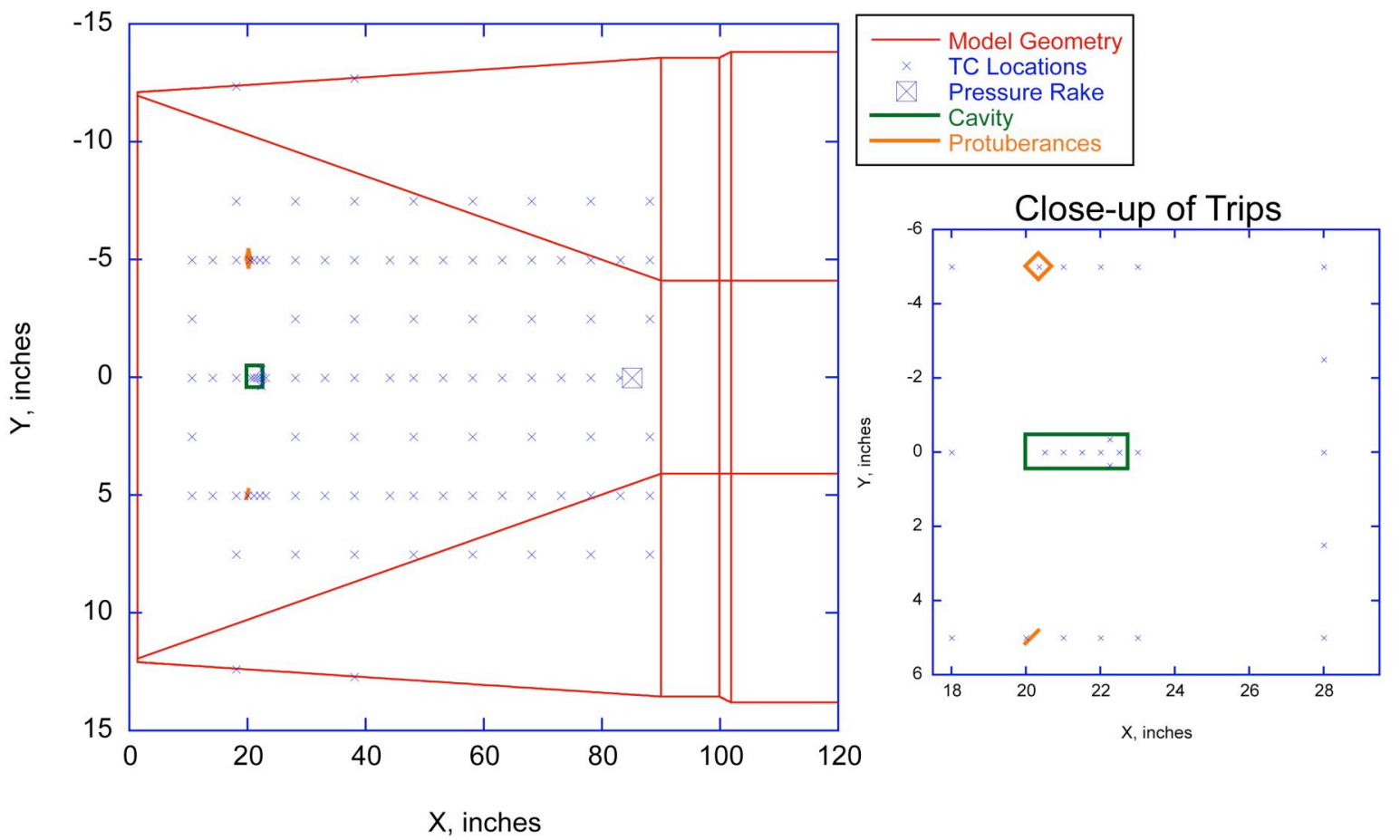

Figure 12. Side B instrumentation layout

7.5. The corresponding $\mathrm{Re}_{\theta} / \mathrm{M}_{\mathrm{e}}$ for these trajectory points are between 80 and 130 , which are in the range of interest for Shuttle. Tables 4 and 5 provide the calculated trip dimensions obtained using the RTF BLT Tool methodologies corresponding to local properties listed in Tables 2 and 3, respectively. Based on feedback from the manufacturer on the largest trip height that can be built integral to the copper surface, 0.0683 -in protuberances at $\mathrm{Y}= \pm 5$-in were selected (see Table 5), which corresponds to the Mach 7 trajectory point and a $k / \delta$ of 0.2724 . The matching cavity based on the RTF ground-based data for the centerline at $\mathrm{X}=20$-in is length 2.749 -in, depth 0.377 -in, and width 0.916-in (see Table 4). These dimensions were selected based on feedback from the RTF Cavity Heating Team who recommended a cavity with a length-to-depth ratio of $L / D=7.3$. Note, since Version 1 of the RTF BLT Tool, as mentioned earlier, is based on the LATCH engineering code and not the GASP code used here, these calculated dimensions cannot be considered exact and analysis continues to define the exact scaling between the two codes. For this reason, rounding off of the calculated dimensions to two significant digits seems appropriate. The final height dimension for both protuberances is 0.07 -in. The final cavity dimensions are 2.75 -in length, 0.38 -in depth, and 0.92-in width.

\section{Instrumentation}

The surface thermocouple layout, shown in Figure 12, was primarily dedicated to provide adequate coverage for identifying the movement of transition during the flight. Of the 99 surface thermocouples, 82 sensors are intended for identifying the transition onset front locations, four sensors for the shoulder regions, and the remaining 13 sensors located in and around the BL trips (shown in the inset of Figure 12). The sensors in the vicinity of the trips are to obtain local heating information during the flight. For the protuberances, one thermocouple is placed on top center of the "pizza box", while another is placed in front of the "gap filler", both with two more behind at $x=21$ and 22-in. On the cavity floor, a distribution of sensors is placed along centerline at $X=20.5,21,21.5,22$, and 22.5-in, while two are placed on at $\mathrm{Y}= \pm 0.35$-in at $\mathrm{x}=22.25$-in. All Side $\mathrm{B}$ sensors are considered low-frequency instrumentation, sampled at 100 sps (all thermocouples, including those on Side A, are sampled at this lower rate).

\section{Post-Flight Analysis}

For Side B, the post-flight analysis will primarily be a comparison of the effectiveness between the three BL trips relative to each other and then to expectations based on the ground-based correlations. The spacing of the surface sensors was selected to provide an accurate mapping of the movement of the transition front (or turbulent wedge) as a function of the trajectory. Some limited trip effectiveness and turbulent wedge mapping studies are being considered in the LaRC 20-In Mach 6 tunnel as part of the post flight analysis. 


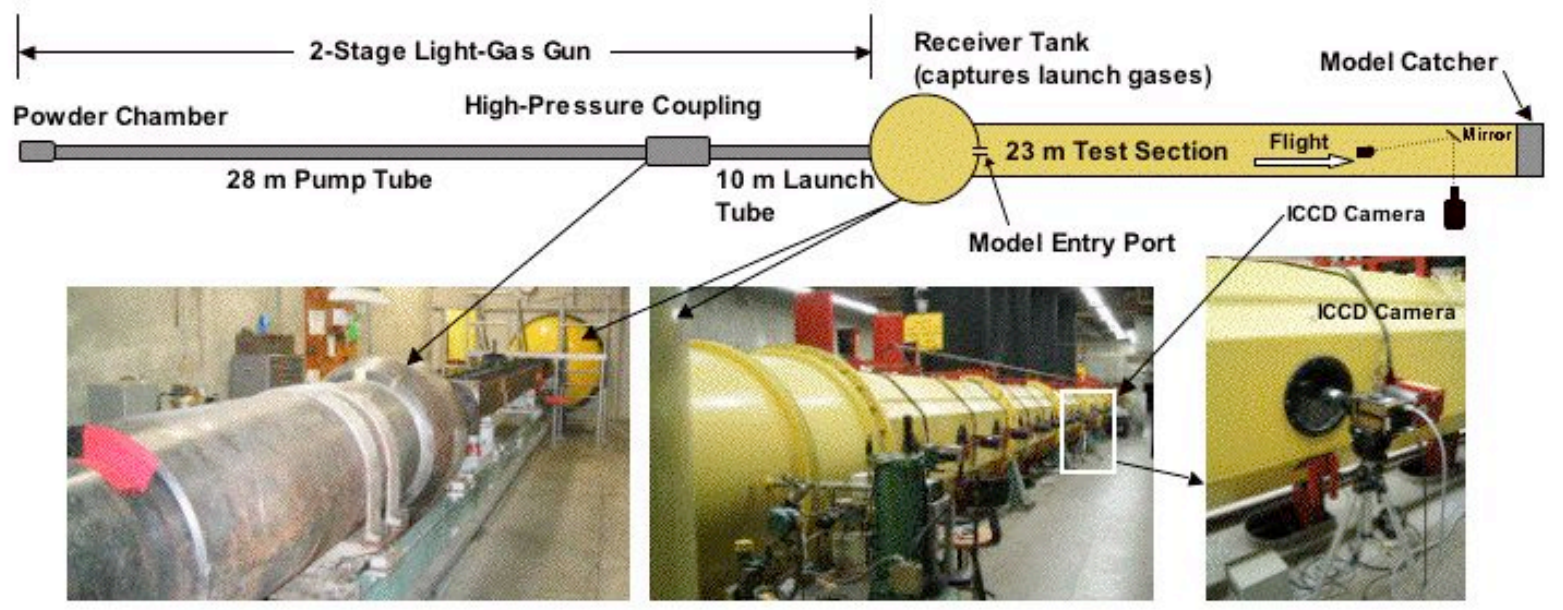

Figure 13. The NASA Ames free flight ballistic range

\section{Ballistic Range}

The Hypersonics project is supporting investigations of transition phenomena induced by isolated and distributed surface roughness under flight-relevant conditions in the Hypervelocity Free-Flight Aerodynamic Facility (HFFAF) at the NASA Ames Research Center. The HFFAF is a ballistic range that uniquely offers the ability to conduct small-scale hypersonic flight experiments in a ground-based facility. ${ }^{16}$ This facility provides a disturbance-free, quiescent environment that matches the high-enthalpy conditions of flight. The test-section gas pressure and composition can be selected, allowing independent control of the Mach and Reynolds numbers, as well as simulation of flight through non-terrestrial atmospheres. While no single facility is capable of matching all flight parameters, carefully designed ballistic-range experiments can provide needed experimental data for bridging the gap between other ground-test facilities (wind tunnels, etc.) and full-scale flight, as well as for validating computational tools. The present ballistic range results represent preliminary, recently acquired data, shown here to illustrate the experimental techniques employed at the ballistic range. Complete analysis will be documented in a subsequent report.

The HFFAF, shown in Figure 13, employs a two-stage light-gas gun to launch individual models on trajectories through a test section that is approximately $1 \mathrm{~m}$ across and $23 \mathrm{~m}$ long, measured from the first optical station to the

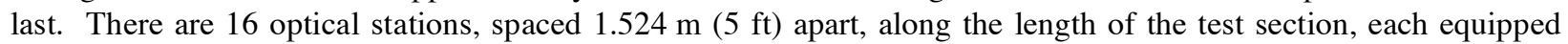
with orthogonal viewing shadowgraph cameras and high-speed timers for recording the flight trajectories (position and angles as functions of time). In addition, individual stations can be equipped with one of several thermal-

(a)

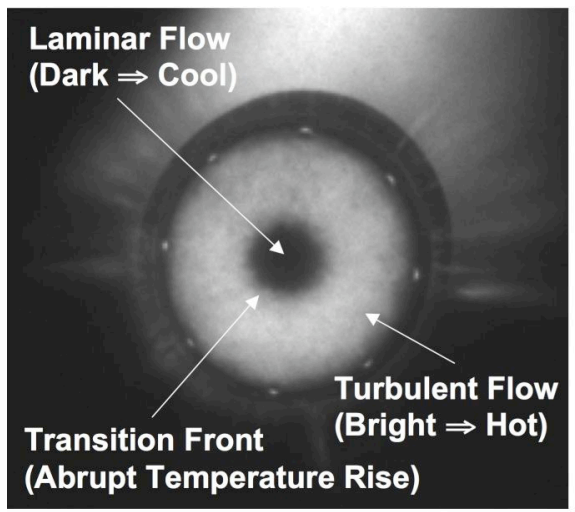

(b)

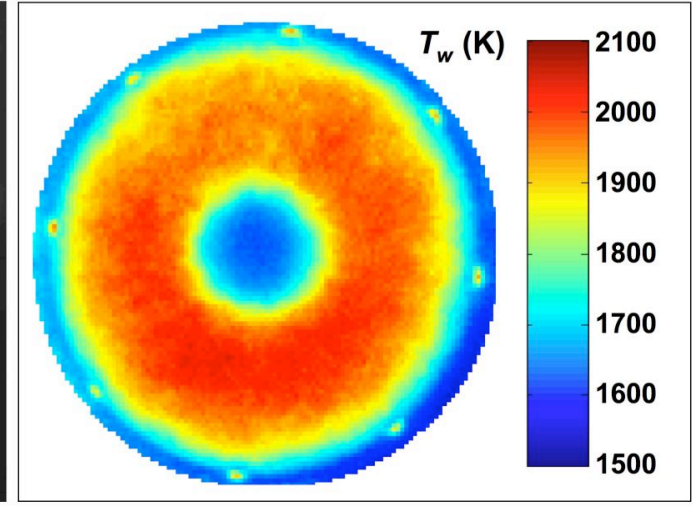

Figure 14. Pre-ablated hemispherical POCO graphite nosetip: $R_{N}=1.905 \mathrm{~cm}, V_{\infty}=4.5 \mathrm{~km} / \mathrm{s}$, $P_{\infty}=0.317 \mathrm{~atm}$; (a) ICCD camera image; (b) global surface temperature distribution 
imaging systems to obtain instantaneous global surface temperature images of the models. ${ }^{17}$ The models are in flight for an additional $10 \mathrm{~m}$ from the exit of the gun barrel to the first optical measurement station, during which time the launch sabot is separated from the model and trapped in the receiver tank. The inner bore diameter of the launch tube is $3.81 \mathrm{~cm}(1.5 \mathrm{in})$. The test-section gas pressure can be set from atmospheric to near vacuum to simulate the atmospheric density at a chosen altitude. Velocities as

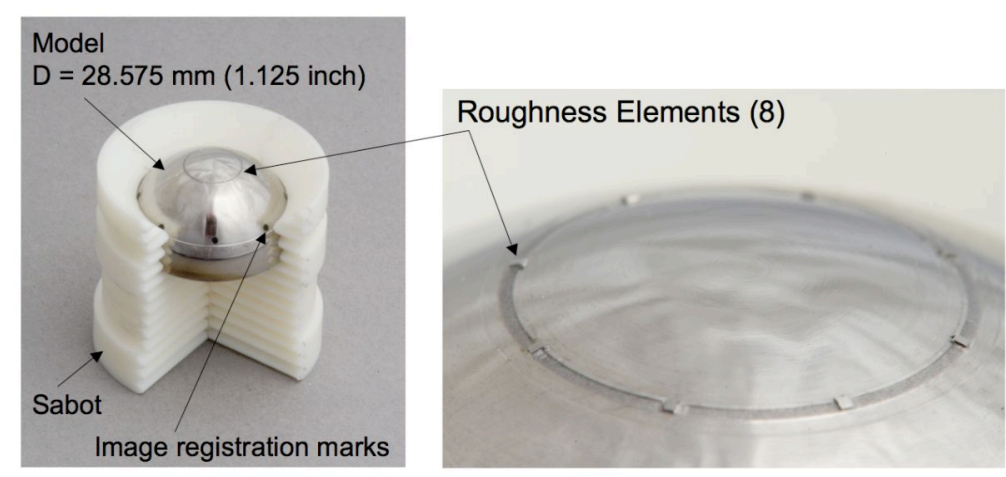

Figure 15. Typically model for ballistic-range experiments high as $8.5 \mathrm{~km} / \mathrm{s}$ have been routinely achieved; however, the launch velocities were around $4.5 \mathrm{~km} / \mathrm{s}$ for the current experiments. Gun-launched models can receive an angle-of-attack perturbation from the gun muzzle blast and sabot separation process. Aerodynamic forces will return a statically stable model to its trim angle of attack (zero degrees in the cases shown here), causing the model to oscillate as the perturbation is damped out. Typical models flown in the HFFAF experience approximately 3 cycles of oscillation, with an oscillation wavelength of about $10 \mathrm{~m}$. The sabot is designed so as to minimize angular rate perturbations induced during the sabot separation process, and the model is designed to maximize the static margin in order to damp out any perturbations. However, the aerodynamics of the muzzle blast and the sabot separation are highly non-linear so it is impossible to completely eliminate angle-of-attack perturbations. For the present studies of transition due to isolated disturbances, care has been taken to minimize launch perturbations. With the current model and sabot design, flights have been achieved with a nominal angle of attack of 0 degrees and maximum oscillations of 2 degrees angle of attack through 2.5 cycles of oscillation.

The onset and progression of transition is determined from thermal images of the surface of the models obtained at various locations along the flight trajectories. The onset of transition is associated with a corresponding increase in surface temperature visible in the thermal images. Figure 14 illustrates this for distributed-roughness-induced transition on a hemispherical nose tip. The image shows a nearly nose-on view, with a cool, laminar-flow region around the stagnation point, and an abrupt rise in temperature marking the transition front. The angle of attack at the time the image was recorded was 1.5 degrees. The maximum angle of attack during the flight was 3.6 degrees. The current experiments are focused on transition induced by isolated protuberances. For these initial experiments a hemispherical model was selected in order to compare these results with previously reported results for distributedroughness-induced transition on hemispherical geometries. ${ }^{18,19}$ Figure 15 shows a typical model and launch sabot, with one segment of the sabot removed for illustrative purposes. The sabot has four segments, which are aerodynamically stripped from the model upon exiting the launch tube. The model is a titanium-alloy hemisphere whose surface has been machined down to reveal eight protuberances, spaced every 45 degrees in the circumferential direction, and located at a given angular distance (20 degrees in this case) from the geometric stagnation point. The protuberances are nominally $56 \mu \mathrm{m}$ (0.0022 inch) high, and $254 \mu \mathrm{m}$ (0.01 inch) on each side. The fabrication method left a shallow circumferential depression between protuberances, as seen in the picture. The depression was less than a quarter of the protrusion height below the surface, and had minimal apparent aerodynamic affect at the conditions tested.

In a recent review ${ }^{18}$ of roughness-induced transition data, Reda showed that, when applying the criticalroughness Reynolds number approach to wind-tunnel data taken along the Shuttle centerline, the transition roughness Reynolds number for isolated roughness was about four times that for three-dimensional, distributed roughness.

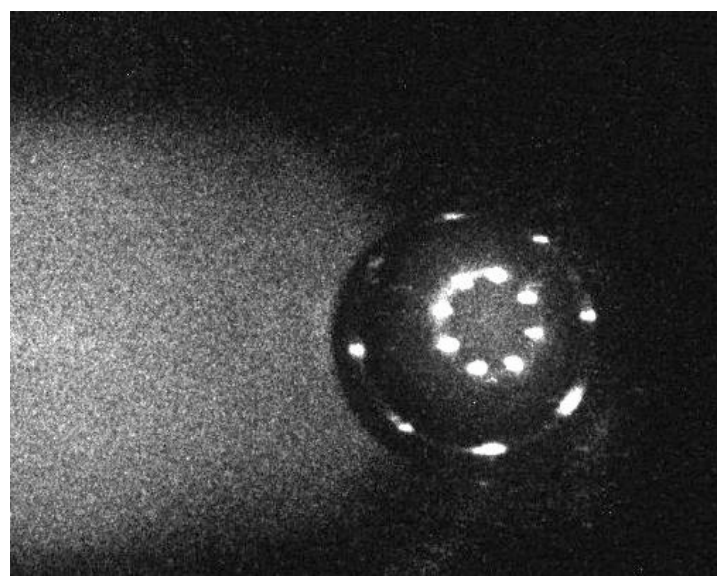

Figure 16. Ballistic-range model in flight: $\mathbf{R}_{\mathbf{N}}=$ $1.429 \mathrm{~cm}, V_{\infty}=4.5 \mathrm{~km} / \mathrm{s}, P_{\infty}=0.15 \mathrm{~atm}$. 
Ignoring potential differences due to configuration and freestream noise effects, this ratio was used as a starting point for determining the critical-roughness Reynolds number for isolated roughness on a hemisphere in comparison to the previously determined value of $\mathrm{Re}_{\mathrm{k}, \mathrm{tr}}=250 \pm 20 \%$ for distributed roughness. ${ }^{18,19}$ Real-gas Navier-Stokes computations were made of the laminar boundary-layer profile on a hemisphere at several freestream pressures and velocities. $\mathrm{Re}_{\mathrm{k}}$ was evaluated at several roughness heights, $\mathrm{k}$, at the planned location of the trip element. For the model shown in Figure 15, turbulent flow was expected behind the protuberances for a freestream pressure around $0.1 \mathrm{~atm}$ at a velocity of $4.5 \mathrm{~km} / \mathrm{s}$. Turbulent flow was not observed, however, as seen in Figure 16, which shows a nearly nose-on view of the projectile in flight at $4.5 \mathrm{~km} / \mathrm{s}$ in a freestream pressure of $0.15 \mathrm{~atm}$. The instantaneous angle of attack was 2.5 degrees, and the maximum angle of attack during the flight was 3.1 degrees. The eight protuberances located 20 degrees from the nose, and the eight image-registration marks located 60 degrees from the nose, are clearly hotter than the surface of the model, but the thermal imprint of a turbulent wake is not seen behind the trips. At higher pressures, the temperature of the trips exceeded the ignition temperature of titanium (around $1450 \mathrm{~K}$ for these condition $\mathrm{s}^{20}$ ) and combustion began during the flight. It is likely that configuration effects cannot be ignored; that is, the favorable pressure gradient on a sphere acts to stabilize the boundary layer, and the transition roughness Reynolds number for isolated roughness is greater than four times that for three-dimensional, distributed roughness. It is also possible that the trips were eroding prior to ignition, thus the actual roughness Reynolds number is less than the expected value. The next generation of models will employ high-temperature ceramic pins for protuberances.

\section{Summary}

The present paper provides details of two planned experimental boundary layer transition studies in support of fundamental hypersonics research. The two studies are the HyBoLT flight experiment and a new ballistic range effort. Details are provided of the objectives and approach associated with each experimental program. The establishment of experimental databases from ground and flight are to provide better understanding of high-speed flows and data to validate and guide the development of simulation and/or engineering tools. The HyBoLT flight experiment is presently scheduled for launch in the fall of 2007. The ballistic range effort is presently on going with some preliminary results presented herein.

\section{Acknowledgments}

The following individuals have provided significant support of the HyBoLT flight experiment: Steve Syrett, Mike Alexander, Manuel Salas, Sharon Graves, Rudy King, Kamran Daryabeigi, Scott Holland, Tom Jentink, Randy Voland, Mujeeb Malik, Ponnampalam Balakumar, George Beeler, Stephen Wilkinson, Mike Scott, Walter Bruce, Vincent Cruz, Carol Harrison and Philip Hamory from NASA; and Warren Frick, Alex Betti, Mike Touma, Greg Wurst, and Dan Tilmont from ATK.

\section{References}

\footnotetext{
${ }^{1}$ Porter, L., "NASA's New Aeronautics Research Program," Presentation at the $45^{\text {th }}$ Annual AIAA Aerospace Sciences Meeting, Jan. 2007.

2 Mansour, N., Pittman, J., and Olsen, L., "Fundamental Aeronautics Hypersonics Project at NASA: Overview," AIAA Paper 2007-4263, June 2007.

${ }^{3}$ Salas, M. D., "A Review of Hypersonics Aerodynamics, Aerothermodynammics, and Plasmadynamics Activities Within NASA's Fundamental Aeronautics Program," AIAA Paper 2007-4264, June 2007.

${ }^{4}$ Wurster, K. E., Riley, C. J., and Zoby, E. V., "Engineering Aerothermal Analysis for X-34 Thermal Protection System Design," Journal of Spacecraft and Rockets, Vol.36, No.2, March-April 1999, pp. 216-228.

${ }^{5}$ Reshotko, E., "Boundary Layer Stability and Transition," Annual Review of Fluid Mechanics, Vol. 8, pp. 311-349, 1976.

${ }^{6}$ Malik, M. R., Li, F., Choudhari, M. M., and Chang, C. L., "Secondary instability of crossflow vortices and swept-wing boundary-layer transition", J. Fluid Mechanics, Vol. 399, pp. 85-115, 1999.

${ }^{7}$ Malik, M. R., "Prediction and Control of Transition in Supersonic and Hypersonic Boundary Layers," AIAA Journal, Vol. 27, No. 11, pp. 1487-1493, 1989.

${ }^{8}$ Reshotko, E., “Transition Issues for Atmospheric Entry,” AIAA Paper 2007-0304, Jan. 2007.

${ }^{9}$ Berry, S. A., Horvath, T. J., Greene, F. A., Kinder, G. R., and Wang, K. C., "Overview of Boundary Layer Transition Research in Support of Orbiter Return To Flight," AIAA-2006-2918, June 2006.

${ }^{10}$ Campbell, C., Anderson, B., Bourland, G., Bouslog, S., Cassady, A., Horvath, T., Berry, S., Gnoffo, P., Wood, B., Reuther, J., Driver, D., Chao, D., and Picetti, D., “Orbiter Return To Flight Entry Aeroheating,” AIAA-2006-2917, June 2006.
} 
${ }^{11}$ Greene, F. A., and Hamilton, H., "Development of a Boundary Layer Properties Interpolation Tool in Support of Orbiter Return-To-Flight," AIAA-2006-2920, June 2006.

${ }^{12}$ McGinley, C., Berry, S. A., Kinder, G. R., Barnwell, M., Wang, K. C., and Kirk, B. S., "Review of Orbiter Flight Boundary Layer Transition Data," AIAA-2006-2921, June 2006.

${ }^{13}$ Berry, S. A., Horvath, T. J., Cassady, A. M., Kirk, B. S., Wang, K.C., and Hyatt, A. J., "Boundary Layer Transition Results From STS-114," AIAA-2006-2922, June 2006.

${ }^{14}$ Malik, M. R., "eMalik3d: An e $\mathrm{e}^{\mathrm{N}}$ Code for Three-Dimensional Flow over Finite-Swept Wings," High Technology report No. HTC-9502 (version 2), April 1995.

${ }^{15}$ Horvath, T. J., Berry, S. A., Merski, N. R., Berger, K. T., Liechty, D. S., Buck, G. M., and Schneider, S. P., "Shuttle Damage/Repair From the Perspective of Hypersonic Boundary Layer Transition - Experimental Results," AIAA-2006-2918, June 2006.

${ }^{16}$ Strawa, A.W., Chapman, G.T., Canning, T.N., and Arnold, J.O., "The Ballistic Range and Aerothermodynamic Testing," AIAA 88-2015, 15th Aerodynamic Testing Conference, San Diego, CA, May 18-20, 1988.

${ }^{17}$ Wilder, M. C., Reda, D. C., Bogdanoff, D. W, and Prabhu, D., "Free-Flight Measurements of Convective Heat Transfer in Hypersonic Ballistic-Range Environments," AIAA-2007-4404, 39 ${ }^{\text {th }}$ AIAA Thermophysics Conference, June 25-28, 2007.

${ }^{18}$ Reda, D. C., "Review and Synthesis of Roughness-Dominated Transition Correlations for Reentry Applications," Journal of Spacecraft and Rockets, Vol. 39, No. 2, March-April 2002, pp. 161-167.

${ }^{19}$ Reda, D. C., Wilder, M. C., Bogdanoff, D. W, and Prabhu, D., "Transition Experiments on Blunt Bodies with Distributed Roughness in Hypersonic Free Flight," AIAA 2007-306, 45th AIAA Aerospace Sciences Meeting and Exhibit Jan. 8-11, 2007.

${ }^{20}$ Hill, P. R., Adamson, D., Foland, D. H., and Bressette, W. E., "High-temperature oxidation and ignition of metals," NACA-RM-L55L23b, March 26, 1956. 